\title{
LIVROS DIDÁTICOS DE LÍNGUA PORTUGUESA E A DISCURSIVIDADE DA INCLUSÃO DIGITAL
}

\author{
Cristiane Pereira dos SANTOS ${ }^{1}$
}

Ana Maria Di RENZO ${ }^{2}$

\begin{abstract}
Resumo: Este artigo busca compreender, pelos fios do discurso do governo federal, os sentidos constituídos sobre a inserção das novas tecnologias digitais nas escolas públicas brasileiras a partir do Programa Nacional de Tecnologia Educacional - ProInfo e seus efeitos nas práticas de ensino de língua portuguesa. Para tanto, nosso olhar, neste trabalho, direcionou-se para as políticas de língua que estão em circulação nas escolas públicas, a partir de recortes extraídos de dois livros didáticos de língua portuguesa, destinados a alunos do $3^{\circ}$ ano do Ensino Médio, ambos produzidos para serem utilizados por três anos consecutivos (2012 - 2014). Teoricamente, este estudo filia-se à Análise de Discurso de linha materialista em articulação com a história das Ideias Linguísticas (HIL). O funcionamento discursivo do jogo políticoeconômico revelou, a partir de nossas análises, que as políticas de inclusão de tecnologias nas escolas trabalham com a ilusão de igualdade entre sujeitos, quer seja pela inclusão digital, quer seja pela inclusão social.
\end{abstract}

Palavras-chave: Análise de Discurso. Políticas Públicas. Novas Tecnologias de Informação e Comunicação. Escola.

\section{Introdução}

Neste artigo, buscamos compreender, pelos fios do discurso do governo federal, os sentidos constituídos sobre a inserção das novas tecnologias digitais nas escolas públicas brasileiras a partir do Programa Nacional de Tecnologia Educacional - ProInfo e seus efeitos nas práticas de ensino de língua portuguesa.

\footnotetext{
${ }^{1}$ UNEMAT - Universidade do Estado de Mato Grosso - Programa de Pós-Graduação Stricto Sensu em Linguística. Cáceres - Mato Grosso - Brasil. 78200-000 - cris tanynha@ hotmail.com

2 UNEMAT - Universidade do Estado de Mato Grosso - Programa de Pós-Graduação Stricto Sensu em Linguística. Cáceres - Mato Grosso - Brasil. 78200-000 - arenzo@ unemat.br

http://dx.doi.org/10.21165/gel.v13i2.1325
}

Revista do GEL, São Paulo, v. 13, n. 2, p. 37-54, 2016 
Este trabalho é parte de uma reflexão desenvolvida em uma Dissertação de Mestrado, no Programa de Pós-Graduação em Linguística da Universidade do Estado de Mato Grosso UNEMAT. Nessa pesquisa, buscamos refletir sobre as discursividades que atravessam as políticas públicas de inserção das novas Tecnologias de Informação e Comunicação - TICs na escola pública, a partir de recortes de dois programas de governo: Programa Nacional de Tecnologia Educacional - ProInfo e Programa Educação Digital: política para computadores e tablets e seus efeitos nas políticas de língua escrita, em diferentes instrumentos de ensino.

Para tanto, revisitamos a Dissertação e elegemos dois recortes extraídos de dois livros didáticos, destinados a alunos do $3^{\circ}$ ano do Ensino Médio, ambos produzidos para serem utilizados por três anos consecutivos (2012 - 2014), sobre os quais foram lançados novos gestos de interpretação, a fim de colocar em evidência o modo pelo qual as tecnologias digitais estão significadas em práticas de ensino voltadas para a produção de texto em sala de aula.

Para tal discussão, filiamos teoricamente a Análise de Discurso (doravante AD) de linha francesa, a qual tem como objeto de estudo o discurso, ou seja, a língua em movimento, cabendo ao analista de discurso desconstruir sentidos cristalizados para mostrar como o discurso produz sentidos diversos. A Análise de Discurso permite-nos “instalar em uma posição materialista” e, assim, nos "inscrever em uma posição que privilegia a ideia de processo e de articulação entre estrutura e acontecimento num batimento" (ORLANDI, 2012, p.183). Em outras palavras, trabalhar com a $\mathrm{AD}$ é estar em um movimento que vai do tema - objeto de estudo - à descrição e análise dos recortes, enfrentando a opacidade do texto, da linguagem, para retornar ao tema e teoria para revisões e reformulações. Desse modo, para a $\mathrm{AD}$, a linguagem não é transparente e o sentido não é conteúdo.

De acordo com Pêcheux (2009, p. 161), a linguagem não é transparente, pois os sentidos se constituem de acordo com as posições ocupadas pelo sujeito do discurso, determinadas pelas condições históricas e ideológicas. Assim, o sentido não é dado a partir da compreensão de significados isolados, contidos em palavras ou expressões. Os sentidos possíveis são constituídos pelas formações discursivas, isto é, "nas relações que tais palavras, expressões ou proposições mantêm com outras palavras, expressões ou proposições da mesma formação discursiva".

O estudo sobre as políticas de língua e as tecnologias no espaço escolar, especialmente nas aulas de Língua Portuguesa, envolve processos de linguagem que, assim como dito anteriormente, não são neutros, pois são historicamente determinados e neles se inscrevem relações políticas e ideológicas. Orlandi (1998), em sua reflexão produtiva a partir de Pêcheux (1982) e Courtine (1986), ensina-nos que 
A Análise de Discurso trabalha a textualização do político (J. J. Courtine, 1986) sendo que a apreensão dessa textualização vem de uma análise dos gestos de interpretação inscritos na materialidade do texto. Na medida em que o político é constitutivo, a compreensão, a própria leitura, em Análise de Discurso, é política. Em outras palavras, 'a análise de discurso se confronta com a necessidade de abrir conjuntamente a problemática do simbólico e do político' (ORLANDI, 1998 apud PFEIFFER, 2013, p. 233)

Estar na língua é ser afetado pelo simbólico. Assim, “como pensar relações de força, relações de poder sem a ideologia e a constituição dos sujeitos e dos sentidos pela ideologia? Tampouco podemos pensar a sociedade apartada da linguagem, na perspectiva discursiva" (ORLANDI, 2014, p.151). O funcionamento da ideologia, para Pêcheux (1988, p.162), “em geral, como interpelação dos indivíduos em sujeitos se realiza através do complexo das formações ideológicas e fornece a cada sujeito sua realidade, enquanto sistema de evidências e das significações percebidas - aceitas - experimentadas".

Nessa perspectiva, entendemos a política linguística conforme nos orientam os trabalhos desenvolvidos no Brasil no campo da História das Ideias Linguísticas (HIL), uma vez que "o político é indissociável do funcionamento das línguas - e de que não há, portanto, práticas linguísticas cuja natureza não seja política" (DINIZ, 2013, p.55). Desse modo, retomamos Orlandi (2007), quando esta propõe pensar a política linguística, dando-lhe o sentido de político necessário:

Não há possibilidade de se ter língua que não esteja já afetada desde sempre pelo político. Uma língua é um corpo simbólico-político que faz parte das relações entre sujeitos na sua vida social e histórica. Assim, quando pensamos em política de línguas já pensamos de imediato nas formas sociais sendo significadas por e para sujeitos históricos e simbólicos, em suas formas de existência, de experiência, no espaço político de seus sentidos (ORLANDI, 2007, p.08).

Como vimos, o político é constitutivo das relações entre línguas, daí nosso interesse em analisar as políticas linguísticas para compreender as condições de produção que estão em circulação nessas materialidades institucionalizadas no discurso do Estado. Ou seja, os documentos/materialidades em análise são elaborados pelo Estado para direcionar e orientar a prática pedagógica. Os recortes dos dois livros didáticos nos levarão a entender os efeitos de sentido que as práticas de Língua Portuguesa, mediada pelas novas Tecnologias de Informação e Comunicação - TICs, produzem. 


\section{Programa Nacional de Tecnologia Educacional (ProInfo) e seus efeitos de sentidos}

O ProInfo, inicialmente denominado de Programa Nacional de Informática na Educação, foi implementado como política pública governamental, lançado pela Portaria $\mathrm{n}^{\circ}$ 522, de 9 de abril de 1997 pelo então Ministro da Educação e do Desporto, Paulo Renato de Souza. Esse Programa estava sustentado em estudos que se voltavam para a inserção da informática no processo educacional, buscando, dessa forma, promover o uso pedagógico das tecnologias nas escolas públicas. Desse modo,

A crescente e irreversível presença do computador - dos recursos de informática de um modo geral - nos mais corriqueiros atos da vida das pessoas tornou indispensável, como ação de governo, para a informatização da Escola Pública. Uma decorrência da obrigação do poder público de diminuir as diferenças de oportunidade de formação entre os alunos do sistema público de ensino e os da Escola Particular, esta cada vez mais informatizada. (BRASIL, 1997, s/p, grifo nosso).

O direito ao acesso às TICs na educação pelos alunos é, em primeiro lugar, responsabilidade do Estado, uma vez que é seu papel implantar políticas públicas para atender às necessidades da sociedade. As políticas públicas, segundo Dias (2010, p. 50), “entram em cena uma vez que elas vão criar um consenso de igualdade social, de acesso, de oportunidades, mediante a capacitação de sujeitos, o que permitirá ao governo exercer seu poder regulador sem tensão".

Na formulação “obrigação do poder público de diminuir as diferenças de oportunidades de formação entre os alunos do sistema público de ensino e os da Escola Particular" (grifo nosso), observamos que são as políticas públicas que criam um imaginário de igualdade entre escola pública e escola particular pela presença de tecnologias na sala de aula. Assim, há o funcionamento do imaginário de inclusão daqueles que estão à margem da sociedade na era digital. Para Orlandi e Rodríguez-Alcalá (2004), as políticas públicas contemporâneas sustentam-se numa lógica consensual, tendo em vista "a constituição de uma "maioria" através do maior índice possível de "participação" dos "excluídos" e das "minorias sociais" nas diferentes instâncias da vida urbana, como as instituições jurídicas, culturais, tecnológicas, educativas, de lazer” (ORLANDI; RODRÍGUEZ-ALCALÁ, 2004, p.11, grifo das autoras). Assim, as políticas públicas, de um modo geral, produzem, como efeito de sentido, a evidência de serem ferramentas que amenizam as desigualdades impostas na sociedade.

O que temos no discurso do governo é uma meta a ser atingida: a universalização das novas tecnologias nas Escolas públicas e, consequentemente, a melhoria da qualidade da 
educação, uma vez que estar inserido na era digital já estaria significando salto na qualidade educacional.

Dias (2010), ao comentar os estudos de Foucault, faz reflexões importantes sobre a universalização do acesso às tecnologias por meio das políticas públicas de governo.

Ao fazer uma análise da governamentabilidade, Foucault passa pela questão do 'governar', antes que esta palavra tenha assumido seu caráter propriamente político. O que é governar? Numa primeira tomada da palavra vê-se que as pessoas é que são governadas [...]. Os homens só são governados indiretamente. Foucault acredita que "a ideia de um governo de homens é uma ideia cuja origem deve ser buscada no oriente sob a forma das ideias e da organização de um poder de tipo pastoral, depois sob a forma da direção de consciência, da direção das almas" (DIAS, 2010, p. 54).

É importante observarmos que o que aparece nos discursos do ProInfo é o imaginário de um "governo que cuida dos cidadãos". Entretanto, ao lançar uma política pública, ele está apenas cumprindo suas obrigações.

Nessa direção, o ProInfo (1997) é criado com a finalidade de "disseminar o uso pedagógico das tecnologias" no ensino fundamental e médio de escolas públicas de todo o País. Ao trazer o verbo transitivo direto "disseminar", o Estado propõe que as novas ferramentas digitais sejam difundidas, propagadas na escola pública, isto é, o governo difunde, propaga e semeia na escola novos recursos tecnológicos, mas usa essas ferramentas apenas como complemento para as aulas, restringindo-se a implantar a política, silenciando, a um só tempo, as competências que ela exige, tais como formação de professores, planejamento didático que englobe as TICs com os conteúdos ministrados.

Ao possibilitar que as escolas públicas brasileiras disseminem o uso pedagógico das novas ferramentas tecnológicas nas Escolas, o governo pretende que esse acesso gere mais conhecimento. Assim, em seu discurso, o governo quer abranger (disseminar) uma quantidade bastante significativa de alunos incluídos digitalmente, pois, quanto maior for o número de máquinas disponíveis na Escola, maior será o número de incluídos digitalmente. Entendemos que, nesse discurso, o sentido de inclusão se dá pela maior quantidade de máquinas que a Escola possui, e não necessariamente pela qualidade do processo do ensino-aprendizado que está sendo oferecido ao sujeito-aluno.

É nesse sentido de "contribuir com a inclusão digital por meio da ampliação do acesso a computadores, da conexão à rede mundial de computadores e de outras tecnologias digitais, beneficiando a comunidade escolar e a população próxima às escolas" (Decreto Presidencial no 6300), que o ProInfo, iniciado no final do século XX, passa por reformulação no ano de 2007 , 
por meio do Decreto Presidencial n 6300 de 12 de dezembro de 2007. Observamos que, ao longo de uma década e da passagem do século XX para o XXI, ocorre apenas a mudança de nomenclatura. A Portaria 522/1997, que designou a política como Programa Nacional de Informática na Educação, em 2007, foi alterada pelo decreto para Programa Nacional de Tecnologia Educacional. Percebemos nessa nova nomeação a substituição de "Informática na Educação" para "Tecnologia Educacional".

Queremos chamar a atenção para os sentidos de "Informática" e "Tecnologia" presentes nos documentos. Nos dicionários Aurélio (2006) e Michaelis (2012), o termo "informática" significa:

Informática: sf (informa(ção)+suf ática) neol Tratamento automático da informação, ou seja, o emprego da ciência da informação com o computador eletrônico. Tem como base a informação, que por sua vez é resultante da evolução do conceito de documentação; teoria da informação (Dicionário Michaelis, 2012).

Informática: sf. Ciência que visa ao tratamento da informação através do uso de equipamentos da área de processamento de dados. (Mini Dicionário Aurélio - FERREIRA, Aurélio Buarque de Holanda. Editora: Positivo, 2012, p.478).

Já "tecnologia" é assim definido:

Tecnologia: 1 Tratado das artes em geral. 2 Conjunto dos processos especiais relativos a uma determinada arte ou indústria. 3 Linguagem peculiar a um ramo determinado do conhecimento, teórico ou prático. 4 Aplicação dos conhecimentos científicos à produção em geral: Nossa era é a da grande tecnologia. T. de montagem de superfície, Inform: método de fabricação de placas de circuito, no qual os componentes eletrônicos são soldados diretamente sobre a superfície da placa, e não inseridos em orifícios e soldados no local. T. social, Sociol: conjunto de artes e técnicas sociais aplicadas para fundamentar o trabalho social, a planificação e a engenharia, como formas de controle. De alta tecnologia, Eletrôn e Inform: tecnologicamente avançado: Vendemos computadores e vídeos de alta tecnologia. (Dicionário Michaelis, 2012).

Tecnologia: sf. Conjuntos de conhecimentos, esp. princípios científicos, que se aplicam a um determinado ramo de atividade. (Mini Dicionário Aurélio FERREIRA, Aurélio Buarque de Holanda. Editora: Positivo, 2012, p. 768).

Como vimos, a informática atravessa diferentes noções e percursos. Para IDEPAC (2012, p.02), “informática pode ser considerada como significando 'informação automática', ou seja, a utilização de métodos e técnicas no tratamento automático da informação. Para tal, é preciso uma ferramenta adequada: o computador eletrônico". A noção de informática está mais ligada ao campo das ciências, dos métodos de apropriação das máquinas automatizadas. Já a 
noção de tecnologia pode ser pensada para se referir ao uso de computador, e a outras máquinas, para auxiliar no processo de ensino.

A Política Nacional de Informática no Brasil se caracteriza pela Lei de Informática criada pelas ideias dos participantes da Nova República, entre eles: Tancredo Neves, Ulysses Guimarães, Cristina Tavares, Marco Maciel, Severo Gomes e Franco Montoro (MAMMANA, 1985). A expansão da política de informática, que acontecia com mais força em meados dos anos de 1985, pois esta "nasce de olhos abertos, comprometida com a reconstrução da Nação Brasileira, capaz de identificar os seus interesses e discerni-los dos interesses alheios e com a consciência de que seu poder deriva da união entre a competência técnica e a vontade política" (MAMMANA, 1985, p. 19).

Assim, os sentidos, que estavam em jogo com a implantação de uma política de informática brasileira, pautavam-se na finalidade de promover a capacitação de recursos nacionais nas atividades ligadas à informática, e pensando sempre no desenvolvimento social, político, tecnológico e econômico do estado brasileiro. Nas palavras de Guimarães (1985, p. 14), “a Política Nacional de Informática tem, por objetivo básico, a conquista da nossa autonomia tecnológica". Desenvolvimento, nesse caso, está correlacionado à ideia de uso de novas máquinas e na economia de recursos humanos e de tempo, não necessariamente do preparo humano dos envolvidos.

De acordo com Straub (2012), se olharmos para o percurso da Política de Informática no Brasil, com as lentes da teoria da Análise de Discurso, "haveria um deslizamento, compreendido pelo efeito metafórico (PÊCHEUX, 1997) para as noções: informática = computadores; "nação"; "vida das pessoas" (p.50). O que leva a refletir sobre a inserção das tecnologias (especialmente da informática) na educação, pois segundo Dias (2010, p. 66),

[...] ter conhecimento de informática passa, portanto, a fazer parte fundamental do princípio identificatório valorizante da sociedade da informação. $\mathrm{O}$ aprendizado da informática é a motivação para sair de um lugar de não-reconhecimento, de isolamento, de pobreza, de desemprego. Sem esse conhecimento o sujeito é relegado à inutilidade, ele está fora do jogo [...] não é interessante para o Estado que o sujeito esteja fora, pois para que a máquina funcione, é preciso que o sujeito jogue o jogo.

A informática, como vimos, passa a fazer parte da vida das pessoas, fazendo com que haja a necessidade de inserir a educação nessa esfera, isto é, no mundo tecnológico. Mesmo antes da Constituição Federal de 1988 - quando se inicia o processo de institucionalização das Novas Tecnologias nas Escolas - surge o primeiro programa de informática na educação, o Projeto EDUCOM - Educação com Computador (1983), que se caracterizava por ser "o 
primeiro projeto público a tratar da informática educacional, agregou diversos pesquisadores da área e teve por princípio o investimento em pesquisas educacionais" (TAVARES, 2011, p. 01). Ainda, segundo a autora, em 1986, surge o Projeto FORMAR, “desenvolvido pela Unicamp com a colaboração dos outros quatro centros-piloto. O projeto FORMAR era voltado exclusivamente para a capacitação de professores" (p.05). Anos depois, em 1989, é criado o PRONINFE - Programa Nacional de Informática Educativa que, de acordo com Tavares (2011, p. 06),

\begin{abstract}
Possuía um modelo funcional e geograficamente descentralizado, funcionando através de centros de informática na educação espalhados por todo o país. Esses centros contavam com apoio mútuo, divulgando e analisando projetos educacionais, seus objetivos e resultados. Outro ponto forte do PRONINFE era a formação de professores dos três graus (hoje fundamental, médio e superior), bem como na área de educação especial e em nível de pós-graduação. Também visava a pesquisa sobre a utilização da informática na educação, aproveitando a interatividade e a interconectividade que o computador possibilitava.
\end{abstract}

Esses projetos e programas se configuraram apenas como políticas de atendimento em focos específicos e, para algumas escolas, por meio de projetos pilotos, nas quais o processo de inserção das novas tecnologias acontecia de forma bastante lenta e discreta, até chegarmos ao ProInfo (1997), que se caracteriza como política pública brasileira para introdução dos computadores nas escolas da rede pública de ensino e que está vigorando até os dias atuais.

Com a nova denominação "informática na educação" para "tecnologia educacional", temos o deslizamento de sentido do termo "informática" para "tecnologia": tecnologia educacional desliza para crescimento acelerado da economia; atualização das formas de ensinar e aprender; capacitação do sujeito-aluno para o mercado de trabalho. Assim, com a inserção das novas ferramentas digitais no espaço escolar, o governo estaria cumprindo o seu papel de oferecer à sociedade mecanismos para a diminuição da pobreza, isto é, ao universalizar o acesso às novas tecnologias por meio da Escola, o governo estaria cumprindo o seu papel social e econômico com a sociedade: ter nas escolas laboratórios de informática, o que é bem diferente de dizer que as escolas estão utilizando novas tecnologias de ensino, pois até hoje a dificuldade com a banda larga e a capacitação de pessoal persistem.

Desse modo, a informática passa a fazer parte da vida dos alunos recoberta pelo discurso da inserção das TICs que se resumem a novos computadores ou salas equipadas com esses instrumentos, uma vez que as novas tecnologias não estariam tão facilmente acessíveis na própria sala que o professor leciona por meio de tablet, data-show, notebook, smartphones. Isto 
é, produzir a inserção de novas TICs requer uma estrutura ainda maior que enviar para as escolas um laboratório de informática.

\section{Um olhar outro para o livro didático: as tecnologias digitais}

Ao nos propor a refletir sobre o funcionamento das novas tecnologias em livros didáticos de Língua Portuguesa, faz-se necessário entendermos como a política de distribuição e escolha desse instrumental linguístico é estabelecida nas escolas públicas, como parte das condições de produção em sentido amplo em que o Programa Nacional do Livro Didático (PNLD) se sustenta.

Para tal, traçaremos um breve relato sobre o funcionamento do PNLD, responsável pela compra e distribuição das obras didáticas aos alunos do ensino fundamental e médio, na modalidade regular ou Educação de Jovens e Adultos (EJA), para colocarmos em relação à discursividade do PROINFO e seus efeitos nas propostas de ensino de língua escrita desses materiais.

O Livro Didático tem uma particular relação com a cultura escolar. De acordo com Sarian (2012, p. 72), "podemos pensar a construção discursiva do PNLD inscrita no gesto de criação do Instituto Nacional do Livro (INL), em 1929, com a finalidade de legislar sobre políticas do livro didático". Em 1985, o PNLD fazia parte de outras políticas do governo federal, cujo foco era a redemocratização do Brasil. No entanto, o acesso aos livros didáticos ainda não era uma realidade em todo o País, pois muitas escolas e alunos não tinham acesso a esse instrumental.

Com as reformas na educação em 1996, o governo brasileiro passa a ser o maior comprador de livros didáticos do País, distribuindo esse material para a Educação Básica da rede pública. De acordo com dados do portal do Fundo Nacional de Desenvolvimento da Educação (FNDE), foram investidos, desde a criação do PNLD, mais de 333 milhões de reais em livros para beneficiar mais de 7 milhões de alunos do ensino médio.

A escolha dos livros fica a cargo das escolas, que deverão se manifestar sobre o interesse em fazer parte do Programa mediante adesão formal, observando os prazos, as normas, obrigações e os procedimentos estabelecidos pelo Ministério da Educação.

Esse processo produz o sentido imaginário de que a Escola e os professores têm liberdade de escolha dos livros didáticos: "cada escola escolhe democraticamente, dentre os livros constantes no Guia do PNLD, aqueles que deseja utilizar, levando em consideração seu planejamento pedagógico". 
Dizeres esses que significam como evidentes no processo de entrada dos instrumentais de ensino da escola apagando as relações de força que tencionam a entrada dos livros, iniciado com a submissão das propostas ao edital, passando pela avaliação dos materiais, até chegar à apresentação dos títulos para a escolha dos professores.

São constantes, nesse Guia, resenhas das coleções avaliadas por docentes de instituições de ensino superior e aprovadas previamente pelo MEC, de acordo com os princípios e as orientações estabelecidas pelo Ministério, acompanhadas do nome dos autores e das editoras, os princípios e os critérios que nortearam a avaliação pedagógica e os modelos das fichas de análise a serem preenchidas pelos professores da escola. O FNDE disponibiliza o Guia de livros didáticos em seu portal na internet e envia o mesmo material impresso às escolas cadastradas no censo escolar, que orientará a escolha dos livros ${ }^{3}$. Questões que produzem efeito no modo pelo qual o ensino de língua portuguesa é compreendido pelo MEC e autorizado a circular nas escolas.

No que diz respeito às condições de produção do livro didático em sentido estreito, trazemos para esta reflexão as relações de sentido entre as novas tecnologias e as atividades de produção de textos de livros didáticos, o que compreendemos como um efeito do PROINFO nas políticas de ensino de língua portuguesa em circulação nos instrumentos de ensino.

Desse modo, para dar visibilidade ao modo de funcionamento das TICs nesses instrumentais, recortamos duas propostas de produção textual em circulação em Livros Didáticos de $3^{\circ}$ ano do Ensino Médio, adotados por duas escolas públicas da cidade de Cáceres/MT.

O primeiro Livro Didático (LD1) é da Editora Moderna, tem como autores Leila Lauar Sarmento e Douglas Tufano, professores graduados em Letras e com uma longa carreira em escolas públicas e particulares. Esse livro se organiza obedecendo a uma divisão de conteúdo particular, apresentando, no Sumário, a sequência: Português: Literatura, Gramática e Produção Textual, o que dá visibilidade a uma hierarquia de ensino das áreas e seus conteúdos, que são trabalhados separadamente, sem interação entre eles.

O segundo Livro Didático (LD2) é da editora Saraiva, tem como autores William Roberto Cereja e Thereza Cochar Magalhães, também professores graduados em Letras, sendo o primeiro mestre em Teoria Literária e doutor em Linguística Aplicada e em Análise do Discurso, e a segunda mestre em Estudos Literários. Traz a sequência: Português Linguagens: Literatura, Produção de Texto e Gramática.

\footnotetext{
${ }^{3}$ Outros atravessamentos também se fazem presentes nesse processo de seleção dos livros que compõe o Guia. Em Sarian (2012), encontra-se uma discussão a esse respeito.
} 
Chamamos atenção para o nome das editoras em que os livros foram publicados: Moderna (LD1) e Saraiva (LD2). Editoras pertencentes a grupos considerados de peso no mercado editorial brasileiro, historicamente beneficiadas pelo PNLD, conforme mostram as pesquisas de Höfling (2000) e Soares (2007). Um negócio lucrativo, denominado "negócio dos didáticos" (SOARES, 2007, p.11), que impulsiona o aquecimento do mercado editorial e direciona a autoria desses instrumentais, numa recorrência de nomes que comparecem a cada edital. Um funcionamento que legitima a autoria em circulação no Guia e que produz efeito no modo de significar o ensino de língua e as tecnologias digitais nos livros didáticos. Determinações e administrações de sentido que nos impossibilitam compreender esse processo de adoção do livro didático como efeito de um processo livre de escolhas.

Vejamos como é discursivizada a proposta de produção de texto do LD1 e LD2:

LD1: Comando 1 - Pesquise como vivem os chineses na zona rural. Recorra a livros, revistas, ou a internet. Converse também com professores de História e Geografia. Anote as informações e opiniões mais importantes, dados, testemunhas, citações, exemplos. Forme uma opinião a respeito de tudo o que aprendeu e elabore uma tese, planeje o seu texto (TUFANO; SARMENTO, 2012, p. 339, grifos nossos).

LD2: Produzindo um texto argumentativo escrito:

a) Escolha um dos seguintes temas:

*O direito de sonhar dos jovens de hoje tem sido roubado? superior?

*O ensino médio deve ser profissionalizante ou preparar para o ensino dos jovens?

*A formação profissional ocupa o primeiro lugar nas preocupações

b) Escreva um texto argumentativo sobre o tema.

c) Tenha em vista o perfil dos leitores. Seu texto será divulgado no mural da classe ou do colégio, ou num blog ou num fórum de debates da Internet. Logo, seus leitores serão na maioria jovens como você.

d) Tome uma aposição sobre o assunto e, logo nos primeiros parágrafos, deixe claro qual é o seu ponto de vista.

e) Ao redigir, organize o texto em parágrafos. A introdução pode corresponder a um parágrafo ou, no máximo, dois. Cada um dos argumentos pode corresponder a um parágrafo. Se um argumento for amplo e envolver mais de um aspecto, é possível desenvolvê-lo em dois parágrafos. Para a conclusão, geralmente se destina o último parágrafo.

f) Ao concluir o texto, dê-lhe um título sugestivo e revise-o. Faça alterações, se necessário e, finalmente, divulgue-o. (CEREJA; MAGALHÃES, 2012, p. 62, grifo nosso).

O LD2 apresenta também uma seção destinada à orientação sobre como deve ser confeccionado o mural e os procedimentos a serem adotados para a divulgação dos textos no blog e no fórum de debate, com a finalidade de dar visibilidade às produções dos alunos: 


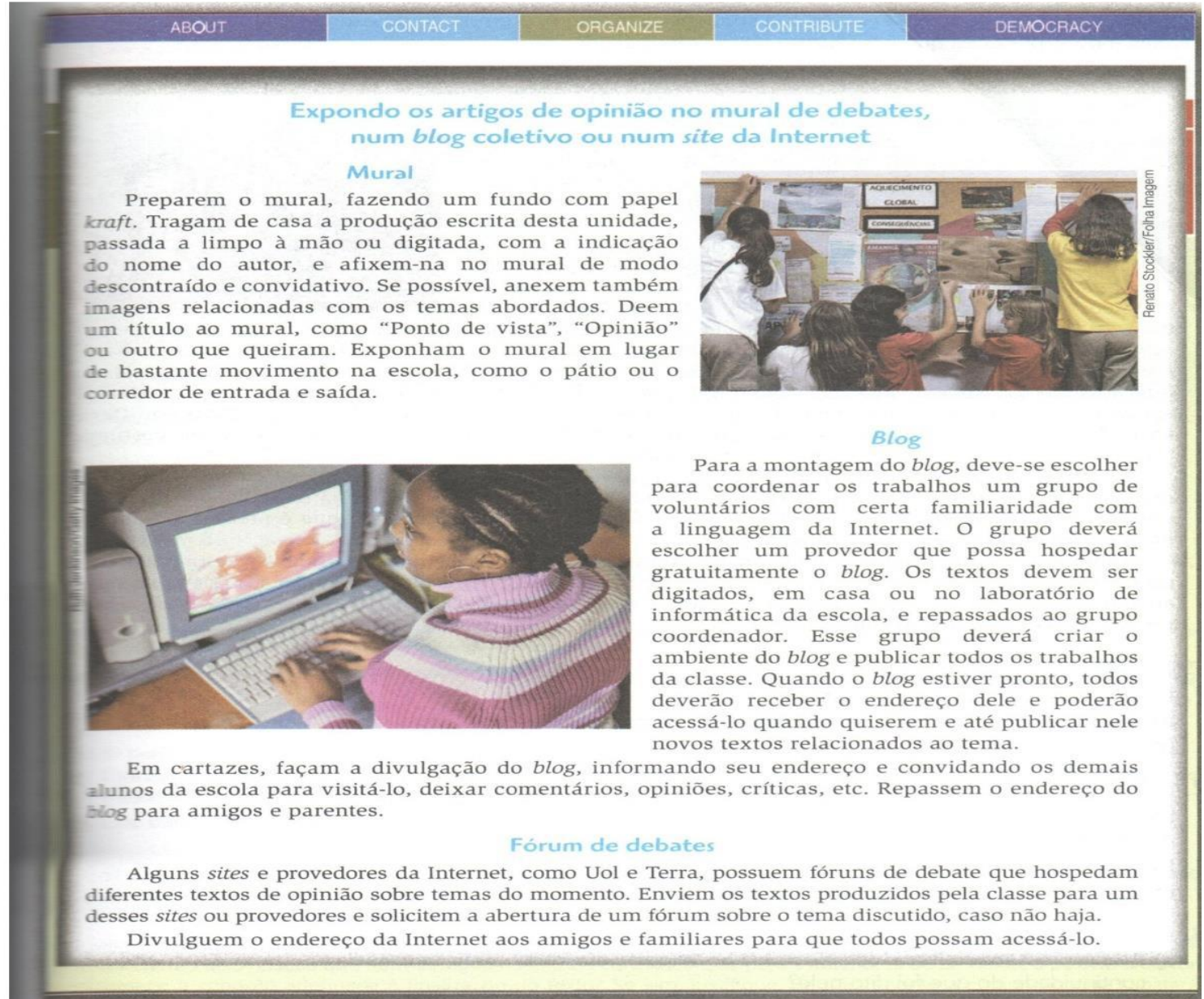

Figura 1 - Expondo os artigos de opinião no mural de debates, num blog coletivo ou num site da Internet

Fonte: Cereja e Magalhães (2012)

Chama-nos atenção, no enunciado dessas atividades, o significante "comando" e o modo pelo qual as atividades foram formuladas, com o emprego de verbos no modo imperativo afirmativo, associado ao modo da "ordem": "pesquise", "recorra", "converse", "anote", "forme", “escolha", “escreva", “tome”, "tenha em vista”, “organize”, “faça", entre outros significantes por nós destacados. Formulações que, em nossa compreensão, vem dizer do modo de constituição desses exercícios, inscritos no discurso pedagógico autoritário (ORLANDI, 1998); uma memória discursiva atualizada nesses instrumentos de ensino do século XXI, que produz o efeito de administração dos sentidos para o sujeito escolarizado, significado como um sujeito consciente que, para bem dizer, deve atender aos "comandos" dos enunciados.

Pousando nosso olhar no "comando" do LD1, que solicita uma proposta de produção de texto sobre a situação social, econômica e política das pessoas mais pobres da China, é pedido ao aluno que, tendo dificuldade de encontrar informações sobre o assunto em livros e revistas, poderá acessar a internet para obtê-las. Dessa forma, o LD1 apresenta as novas ferramentas digitais como suporte para pesquisa extraclasse, fazendo significar a internet em sua 
materialidade empírica, como uma fonte confiável para consultas, como uma grande biblioteca, apagando a materialidade da circulação dos sentidos, pois nem tudo pode e deve ser dito nos livros, nas revistas e também na internet.

Nessa atividade, não se dá espaço para se problematizar, discutir, selecionar, polemizar as informações - aqui significadas como da ordem do empírico - encontradas nessas pesquisas, sobrepondo-as à construção do conhecimento, que é da ordem material (DIAS, 2009). O acesso à informação não garante a construção do conhecimento, mas um trabalho com a leitura em sua materialidade constitutiva, na historicidade do dizer. Nessa proposta do LD1, o trabalho com a leitura reduz-se ao que Orlandi (2008, p.36-37) nomeia de "leitura imediatista", "leitura como decodificação", com vistas à "apreensão de um sentido"; uma concepção de língua que compromete a inscrição do dizer do sujeito aluno na repetição histórica, "formulação que produz um dizer no meio dos outros, inscrevendo o que se diz na memória constitutiva" (ORLANDI, 1998, p.14).

Nessa proposta de atividades do LD1, projeta-se um imaginário de aluno ideal: se o aluno tem interesse em aprofundar o assunto trabalhado naquela aula, ele pode acessar os sites e consultar os demais materiais que lhe foram sugeridos, o que nos faz compreender que tal ação dependerá do investimento do aluno em sua formação. Desse modo, ao aluno imputa-se a responsabilidade de traçar seu percurso de estudo, prática associada a uma concepção de ensino que responsabiliza o sujeito aluno pelo seu próprio aprendizado, apagando o papel do Estado, da Escola e do Professor, ao reduzir o trabalho com as informações a uma "conversa" com professores de História e Geografia.

Regularidades de sentido também comparecerem nos recortes selecionados do LD2. Elegemos a atividade do Capítulo 5, da Unidade 3, que objetiva trabalhar com a produção de texto a partir do "texto argumentativo: a seleção de argumento". Para trabalhar com esse gênero, o livro traz vários textos a respeito dessa temática. Por fim, no "comando" solicita-se que cada aluno produza um texto argumentativo e entregue-o ao professor. Após a correção feita pelo professor, o livro propõe que o texto seja divulgado aos demais colegas da escola. Para isso, poderá ser exposto em um mural, ou num site da internet, ou num blog.

Nessa atividade, autoriza-se um modo de circulação da produção escrita na rede, num gesto em que as TICs são significadas como ferramentas de publicização do dizer, nas proposições de montagem de um blog ou um fórum na internet para compartilhar textos produzidos por eles, tal como lemos na Figura 1. Para tal, os autores do livro recomendam a utilização da sala do laboratório de informática da escola para digitar os textos, tomada como em perfeitas condições para o uso, homogeneizando as condições materiais das escolas públicas 
deste país. Nessa discursividade, silenciam-se também os percentuais atingidos pelo Programa, que do universo de 44,8 mil escolas públicas, 13,40\% foram atendidas com a instalação de laboratório de informática. Um sentido que compreendemos como contraditório no funcionamento da discursividade do LD2.

Embora esses dados apontem para uma estatística datada dos anos 90, pela nossa experiência profissional, conhecemos de perto a "realidade" de muitas escolas públicas de nosso município, o que nos permite afirmar que o acesso à internet nos estabelecimentos de ensino ainda não é privilégio de todos os alunos. Embora saibamos que, para muitos alunos, o acesso à rede se dá em suas residências, lan houses ou por meio de aparelhos celulares, não se pode cair na evidência do "todos conectados", pois as formas de acesso ainda não são para todos, nem na generalidade da exclusão digital, quando se considera que nossa sociedade é atravessada pelo digital.

Se, por um lado, a possibilidade de circulação dos dizeres inscreve as produções textuais na instância do publicável na rede mundial de computadores, dando visibilidade e legitimidade a produções que, na maior parte das vezes, não transcendem os muros da sala de aula, tampouco da escola, por outro lado, continua funcionando, nessas produções, o efeito autoritário do discurso pedagógico, inscrito na textualidade dos “comandos".

Chama-nos especial atenção o modo pelo qual a proposta de produção escrita do LD2 é discursivizada, sobretudo em relação ao direcionamento temático a partir do qual será produzido o texto argumentativo - “a) Escolha um dos seguintes temas" -, no total de três, e a rigidez do "comando" no que tange à estrutura do texto dissertativo-argumentativo:

A introdução pode corresponder a um parágrafo ou, no máximo, dois. Cada um dos argumentos pode corresponder a um parágrafo. Se um argumento for amplo e envolver mais de um aspecto, é possível desenvolvê-lo em dois parágrafos. Para a conclusão, geralmente se destina o último parágrafo. (CEREJA; MAGALHÃES, 2012, grifos nossos).

Como marca de uma regularidade, esse processo de administração dos sentidos, sinalizado pelo emprego de verbos no modo imperativo, o estabelecimento de três temas e a rigidez da estrutura da dissertação, interdita o trabalho da interpretação do sujeito, como se o sentido não pudesse ser outro: efeito da ideologia, do esquecimento número 2 de que nos fala Pêcheux (2009) e que Orlandi (2007, p.35) explicita ao dizer que, por esse esquecimento, "pensamos que o que dizemos só pode ser dito com aquelas palavras e não com outras, que só pode ser assim". 
A ênfase, aqui, bem como no "comando" do LD1, está no produto, na elaboração de uma tese, fruto de uma "opinião" de um sujeito centrado, e não no processo de produção do texto de um sujeito que é, antes, posição dentre outras. Não se dá abertura, nessas atividades, para o que Lagazzi (2006, p.93) compreende como o ponto fundamental para o aprendizado da autoria: uma "prática em concomitância", na qual "o autor se constitui à medida que o texto se configura", processo no qual se dá vazão aos sentidos e possibilidade de o sujeito inscrever o seu dizer na historicidade dos sentidos.

\section{Considerações finais}

Pensar as novas tecnologias na Escola, em especial, a partir do Programa Nacional de Tecnologia Digital (2007), como uma política pública que visa à inclusão digital e à melhoria da qualidade de ensino, implica uma reflexão sobre políticas de língua que circulam nesse programa. O estudo sobre essas políticas acerca das tecnologias no espaço escolar, especialmente nas aulas de Língua Portuguesa, envolve processos de linguagem que não são neutros, pois são historicamente determinados e neles se inscrevem relações políticas e ideológicas.

Para que se obtenha um resultado satisfatório na melhoria da qualidade do ensino de língua, não basta usar as tecnologias digitais como suporte, se as perguntas feitas por meio delas apontarem para um fechamento dos sentidos no trabalho com a leitura e a escrita, como é próprio do livro didático. Como nos ensina Orlandi (2008, p.36-37), "não é o acesso ao instrumento em si que muda as relações sociais, mas o modo de sua apropriação, no qual estão atestadas as marcas de quem se apropria dele". Há de se rever, portanto, as concepções de língua, de sujeito e de tecnologia que sustentam as políticas linguísticas propostas nos instrumentais de ensino.

Fazer inclusão digital não é usar a internet apenas para pesquisar algo na rede para enriquecer as produções de texto. Esse modo de apropriação do computador, da internet, tablet, celular, etc., significado como "novo", na verdade, está sustentando as velhas práticas autoritárias de ensino, pois as propostas de atividades não se deslocaram para uma nova abordagem que repensa a relação língua, sujeito e sentido na sua materialidade constitutiva.

Assim, as produções de texto, tal como propostas nos LD 1 e LD 2, inscrevem-nas no "lugar do mesmo e da repetição, lugar de que a historicidade se retira e o sujeito é só uma imagem já pré-fixada. Espaço dos silêncios da memória” (ORLANDI, 2014, p.19). 
SANTOS, Cristiane Pereira dos; RENZO, Ana Maria Di. Portuguese textbooks and the discourse of digital inclusion. Revista do GEL, São Paulo, v. 13, n. 2, p. 37-54, 2016.

Abstract: This article seeks to understand, by the speech lines of the federal government, the directions provided on the inclusion of new digital technologies in Brazilian public schools from the National Educational Technology Program - ProInfo and its effects on the practices of Portuguese language teaching. For this reason, at this work, we looked at language policies that are in circulation in public schools, from cuttings taken from two textbooks of Portuguese language designed for students of the $12^{\text {th }}$ year of High School, both produced to be used for three consecutive years (2012-2014). Theoretically, this study joins the materialistic Discourse Analysis in conjunction with the history of Linguistic Ideas - (HIL). The discursive functioning of the political-economic game revealed, from our analysis, that the inclusion technology policies in schools work with the illusion of equality between subjects, either for digital or social inclusion.

Keywords: Discourse Analysis. Public Policies. New Information and Communication Technologies. School.

\section{Referências}

BRASIL. Ministério da Educação, Secretaria de Educação a Distância. - ProInfo. Programa Nacional de Informática na Educação. POPPOVIC, P. P. (Secretário de Educação a Distância). Brasília, 1997. [Doc. Eletrônico: 〈http://www.proinfo.mec.gov.br/> (doc. original 11/mar/97).]. Acesso em: 14 jan. 2015.

Ministério da Educação e do Desporto. Portaria no 522, de 9 de abril de 1997. Disponível em: 〈http://www.dominiopublico.gov.br/pesquisa/PesquisaObraForm.jsp >. Acesso em: 18 mar. 2015.

- Ministério da Educação e Cultura. Secretaria de Ensino Fundamental (SEF). Parâmetros Curriculares Nacionais. Brasília: MEC/SEF, 1998.

PRESIDÊNCIA DA REPÚBLICA. Decreto n 6.300, de 12 de Dezembro de 2007. Dispõe sobre o Programa Nacional de Tecnologia Educacional - ProInfo. Decreto on-line. Disponível em: $\quad$ http://www.planalto.gov.br/ccivil_03/_Ato20072010/2007/Decreto/D6300.htm>. Acesso em: 18 mar. 2015.

CEREJA, W. R.; MAGALHÃES, T. C. Português Linguagens: literatura, produção de texto e gramática. São Paulo: Saraiva, 2012.

DIAS, C. P. Telecentros como políticas públicas de inclusão digital: da administração da vida na cidade. In: ORLANDI, E. O. (Org.). A produção do consenso nas políticas públicas urbanas. Campinas: Editora RG, 2010. p.43-73.

Imagens e metáforas do mundo. Rua [online], v.2, n.15, p.15-28, 2009. 
DINIZ, L. R. A. O Conceito de "Política Linguística": reflexões a partir do diálogo entre a História das Ideias Linguísticas, Análise de Discurso e a Semântica do Acontecimento. In: MASSMANN, D.; COSTA, G. (Orgs). Linguagem e Historicidade. Campinas: RG, 2013.

FERrEIRA, A. B. de H. Míni Dicionário da Língua Portuguesa. 6. ed. Curitiba: Positivo, 2006.

GUIMARÃES, U. A informática e a construção do futuro. A informática e a nova república. São Paulo: Editora de Humanismo, Ciência e Tecnologia "HUCITEC" LTDA, 1985.

HÖFLING, E. de M. Notas para discussão quanto à implementação de programas de governo: em foco o Programa Nacional do Livro Didático. Educação e Sociedade. Campinas, ano XXI, n. 70, p.159-170, 2000.

IDEPAC. Fundação Sergio Contente. Informática: semiintensivo, avulso. 2012. Disponível em <www.idepac.org.br/cursos.php>. Acesso em: 15 jan. 2015.

LAGAZZI, S. Texto e autoria. In: ORLANDI, E. P.; LAGAZZI-RODRIGUES, S. (Orgs.). Discurso e textualidade. Campinas: Pontes, 2006. p.81-103.

MAMMANA, C. A informática e a nova república. Informática e a nova república. São Paulo: Editora de Humanismo, Ciência e Tecnologia "HUCITEC" LTDA, 1985.

MICHAELIS: moderno dicionário da língua portuguesa. São Paulo: Companhia Melhoramentos, 2012 (Dicionários Michaelis). 2259 p.

ORLANDI, E. P. Discursos e museus: da memória e do esquecimento. Entremeios, Revista de Estudos do Discurso, Pouso Alegre, v.9, p.1- 8, jul. 2014.

Discurso em análise: sujeito, sentido, ideologia. 2. ed. Campinas: Pontes, 2012.

Discurso e leitura. 8. ed. São Paulo: Cortez, 2008.

As formas do silêncio: no movimento dos sentidos. 6. ed. Campinas: Editora da UNICAMP, 2007. 19, 1998.

Paráfrase e polissemia: a fluidez nos limites do simbólico. Rua, Campinas, n.4, p.9-

ORLANDI, E. P.; RODRÍGUEZ-ALCALÁ, C. A Produção do Consenso nas Políticas Públicas Urbanas: Entre o Administrativo e o Jurídico. In: RODRÍGUEZ-ALCALÁ, C. (Org.). Escritos 8. Cidade, Consenso e Políticas Públicas. Campinas Unicamp/Labeurb, 2004.

PÊCHEUX, M. Semântica e discurso.4. ed. Campinas: Editora da UNICAMP, 2009.

PFEIFFER, C. Língua em museu: institucionalização de um nós no recobrimento de um resto histórico. Letras, Santa Maria, v. 23, n. 46, p. 225-244, jan./jun. 2013. 
SARIAN, M. C. A injunção ao novo e a repetição do velho: um olhar discursivo ao Programa um Computador Por Aluno (Prouca). 2012. 274 f. Tese (Doutorado em Linguística) - Instituto de Estudos da Linguagem, Universidade Estadual de Campinas, Campinas, 2012.

SOARES, R. P. Texto para discussão n⿳1307: compras governamentais para o Programa Nacional do Livro Didático: uma discussão sobre a eficiência do governo. Brasília: IPEA, 2007.

STRAUB, S. L. W. Política de informática na educação: o discurso governamental. 2012. 198 f. Tese (Doutorado em Linguística) - Instituto de Estudos da Linguagem, Universidade Estadual de Campinas, Campinas, 2012.

TAVARES, N. R. B. História da informática educacional no Brasil observada a partir de três projetos públicos. Universidade de São Paulo. 2011.

TUFANO, D.; SARMENTO, L. L. Português: literatura, gramática, produção de texto. São Paulo: Moderna, 2012.

Submetido em 01/04/2016

Aceito em 25/05/2016. 